Jorge Baraona GonzÁlez, LA NULIDAD DE LOS ACTOS JURÍDICOS, Bogotá, PonTIFICIA UNIVERSIDAD JAVERIANAIBAÑEZ, 2012, 184 PP.

Los modernos instrumentos de Derecho Contractual uniforme, tan examinados hoy día, imponen la necesidad de volver a estudiar, dentro de otras cosas, las reglas sobre perfeccionamiento y nulidad de los contratos, y más en general de los actos jurídicos. Si bien a partir de ellos la doctrina, por lo menos nacional, se ha abocado con preferencia al ámbito de los remedios contractuales, es necesario recordar que estos textos contienen normas sobre la formación y vicios de los contratos y sus consecuencias. Sobre todo, la tarea se tornará más demandante si estamos a las vísperas de la entrega de los Principios Latinoamericanos de Derecho de los Contratos, que también contendrán (según se ha observado en los borradores parciales puestos a disposición del público $\mathrm{y}$ en los informes nacionales que se han elaborado con ocasión de ellos) reglas sobre formación y nulidad de los contratos. Sin embargo, mientras que a partir de éstos no se conciban propuestas concretas de reforma a los textos legales vigentes, bien vale la pena seguir estudiando nuestra legislación vigente.

Sobre la materia, nuestros textos legales han generado no poca discusión doctrinaria y jurisprudencial. Las visiones en algunos puntos son bastante encontradas, al punto de generar escuelas como la de la inexistencia y nulidad, disputas que se mantienen hasta nuestros días. Los planteamientos y consecuencias dogmáticas que se adopten en cada caso influyen sustancialmente en la estructuración del régimen de perfección de la gran mayoría de actos jurídicos, en especial en el orden patrimonial.

La obra en comento, La nulidad de los actos jurídicos de autoría del profesor de la Universidad de los Andes Jorge Baraona González, trata precisamente de uno de los aspectos más importantes de la teoría general del acto jurídico, tal como su título lo sugiere. El trabajo contiene algunas 
reflexiones del autor ya conocidas previamente sobre el régimen de la nulidad en el Código Civil, pero, además, contempla algunos puntos inéditos hasta la fecha. Este trabajo se publicó para el público colombiano, sin embargo, su redacción se funda en el Código Civil chileno. Es bien sabido que el código de dicho país es prácticamente el mismo que el nuestro, por lo que el estudio sirve para la dogmática de ambos países, y no sólo para efectos comparativos.

Tal como señalamos, y lo hace ver el autor en la introducción, algunas de sus reflexiones ya nos eran conocidas. En efecto, es uno de los profesores contemporáneos que más dedicación le ha dado al tema de la nulidad y la rescisión en el último 334 tiempo. Con todo, el hecho que se hayan estructurado estos trabajos bajo la forma de libro nos ofrece en forma sistemática su pensamiento sobre la materia. Estas ideas que se encontraban en trabajos dispersos hasta antes de la obra, había que juntarlas para comprender su teoría sobre la nulidad. Hoy, este trabajo se ha hecho más fácil sobre todo para el lector no investigador.

A nuestro entender, hay dos puntos sumamente fuertes en su planteamiento sobre la nulidad:

- Uno, es la idea del mantenimiento de la inexistencia como forma de ineficacia de los actos jurídicos y

- El otro es la función que cumple la nulidad absoluta y relativa en el sistema anulatorio del Código Civil.
Sobre la inexistencia, el autor se desmarca de la doctrina tradicional en Chile que sostiene que operaría por falta de los requisitos de existencia de los actos jurídicos. Jorge Baraona opina que la inexistencia, al no estar sistematizada en el Código Civil, no puede considerarse como una categoría rígida sobre la base de la ausencia de ciertos requisitos, sino que debe analizarse a la luz de la regularidad del acto en función de su apariencia formal u ostensibilidad. Por lo tanto, acto inexistente será el que no tiene esta apariencia o no es ostensible, y nulo, por el contrario, el que sí la tiene. Esta diferencia permitiría distinguir con claridad los actos que son inexistentes de los nulos. $\mathrm{Si}$ tomamos la postura tradicional en Chile, la verdad es que no es clara la diferencia entre un acto inexistente, por ejemplo, que no tenga objeto o causa, que si se declarara la nulidad por objeto o causa ilícita.

Así, por ejemplo, podemos traer a colación un reciente fallo de la Corte Suprema en que se plantea la cuestión: Agrícola Pecuaria S.A. con Agrícola Super Limitada ${ }^{1}$. En este caso sobre cumplimiento de contrato, se discutió si una venta de una servidumbre de tránsito sobre un camino público era nula de nulidad absoluta o, bien, inexistente, puesto que se trata de la venta de una cosa incomerciable. El tribunal de segunda instancia declaró la inexistencia

${ }^{1}$ Corte Suprema, 28 de noviembre de 2012, rol N 4537-10,cita microiuris: MJJ33941. 
del contrato, puesto que faltaría uno de los requisitos del objeto, cual es su comerciabilidad, no obstante, la Corte Suprema declaró en este caso que en propiedad debía procederse a la nulidad absoluta de la servidumbre toda vez que habría enajenación de una cosa incomerciable ${ }^{2}$. En el considerando $18^{\circ}$, la Corte rechaza el recurso de casación:

"Que, sin perjuicio de lo anterior, la ineficacia del contrato, sea por inexistencia o por la declaración de nulidad absoluta es prácticamente equivalente, pues en ambos casos se supone que el contrato nunca existió ni llegó a producir efecto alguno, por lo que la sentencia que rechazó la demanda y que declaró la inexistencia produce los mismos efectos que si hubiera rechazado la demanda declarando la nulidad absoluta del contrato, lo que determina que el error antes mencionado no tiene influencia en lo dispositivo de la sentencia y, por consiguiente que el recurso deba ser rechazado" (énfasis añadido).

La diferencia importante en este caso está en que si fuera la nulidad la sanción, se podría aplicar la restricción para alegarla al que sabía o debía saber el vicio que lo invalidaba (obviamente no en la inexistencia), cuestión que en considerandos pos-

${ }^{2}$ Art. $1464 \mathrm{~N}^{\circ} 1$ del Código Civil. teriores rechaza la Corte Suprema porque no fue objeto de discusión en el juicio.

$\mathrm{Si}$ interpretamos bien el pensamiento de Jorge Baraona, el criterio de la apariencia parece dejar relegados a la inexistencia aquellos actos que ostensiblemente no lo son, de aquéllos que sí lo son, que serían sancionados con nulidad. Así, en el caso, si aplicamos de forma correcta la tesis del autor, el fallo debió haberse resuelto por vía de nulidad, como lo hizo la Corte, pero por una razón distinta: existía un sustrato contractual ostensible. Esta interpretación dejaría como ociosa aquélla que estima que la falta de los requisitos del objeto, como lo era la comercialidad del mismo en el caso, se sancione con inexistencia, pero si hay enajenación de una cosa incomerciable (o compraventa en el caso, por aplicación del art. 1810) la sanción será la nulidad.

Volviendo al comentario de la obra, la nulidad, ya absoluta ya relativa, es considerada por Jorge Baraona como una sanción legal

"cuya función básica es privar de efecto a un acto; todo ello en servicio a la majestad $u$ obligatoriedad de la ley" (p. 45, énfasis añadido).

La función primordial de toda nulidad es salvaguardar la legalidad de los actos, función que se desprendería de lo dispuesto en los arts. 1681, 10 y 11 del Código Civil, sumado al régimen de obligatoriedad de la ley 
de los arts. 6 y 7 del mismo cuerpo. De esto se desprenden dos cosas:

- En primer lugar, la nulidad siempre opera por vulneración de una norma legal, incluso la nulidad relativa que la doctrina deja supeditada al interés particular.

- En segundo lugar, la nulidad siempre sirve al interés general, incluso nuevamente la nulidad relativa, como es común que se explique la nulidad relativa.

De hecho, no parece coherente sostener que la nulidad relativa, dentro de otras cosas, proteja a ciertos incapaces y la vez sirva al interés privado. el cumplimiento de la ley, lo que parece ser una explicación unitaria y más convincente que la tradicional.

Por esta razón nos parecen acertadas las dos subfunciones que Jorge Baraona detecta de la nulidad:

- por un lado, contiene una función sancionatoria que tiene por objetivo reprimir los actos que no se ejecutan de conformidad a la ley y

- por otro, hay una función preventiva de actos que no se ejecuten de acuerdo con la normativa vigente.

Esta visión de la nulidad sobre la base de sus funciones, a nuestro entender, hace más comprensible el estudio del régimen anulatorio.

El recurso habitual al estudio de las normas precisas más que a su fundamento, a veces nubla la idea de que se encuentra implícito en el sistema de nulidad, es decir, el por qué ciertos actos deben ser anulados. Como afirma el mismo autor, hay detrás de todo esto una política legislativa de nulidades, que sobre la base de sus funciones se hace más entendible con esta explicación.

Luego de explicar el fundamento común de la nulidad, el autor dedica dos capítulos consecutivos al estudio, primero de la nulidad absoluta y luego de la relativa.

Sobre la nulidad absoluta, asume una postura que se encontraba desterrada hace bastante tiempo en la doctrina (la asumió originalmente José Clemente Fabres y luego fue atacada con contundencia por Luis Claro): la nulidad absoluta opera de pleno derecho. Esto diferenciaría aún más los dos tipos de nulidades. El punto sobre la operatividad de la nulidad absoluta y la función de la sentencia tiene consecuencias prácticas: la situación de los pagos efectuados por una de las partes a la otra con fundamento en un acto nulo de nulidad absoluta. Porque claro, cuando las obligaciones no se han cumplido la sentencia hace inexigible las obligaciones en apariencia válidas. El problema dogmático es la conexión entre las acciones restitutorias previstas en los arts. $1687 \mathrm{y}$ 1689 y la sentencia de nulidad. La explicación tradicional señala que la sentencia del juez es declarativa y ello daría lugar a las acciones resti- 
tutorias. Pero esto no se condice con la idea que un acto que era válido ab initio (por lo menos presumiblemente) pase luego, por la sentencia, a ser nulo. En realidad, sucede que el acto siempre fue nulo (o por lo menos anulable). Y, por tanto, cabe determinar porqué, por una parte, antes de la sentencia hay derecho para retener el pago, y después de la sentencia se activa el régimen restitutorio establecido a propósito de la nulidad. La idea del autor es que hay pago de lo no debido, y los deberes de restitución se activan con la declaración de nulidad. Esto, según Jorge Baraona, confirmaría que la nulidad absoluta opera de pleno derecho y sería afín con el régimen restitutorio del Código, y con el régimen común en el Derecho extranjero.

Un segundo punto de interés es el saneamiento de la nulidad por el transcurso del tiempo, que hoy es de diez años. La solución del Código es original, porque la nulidad absoluta en Derecho Comparado no prescribe (o la sanción equivalente). Sostiene el autor que este plazo, más que de prescripción extintiva es de caducidad. La diferencia parece ser sutil. Jorge Baraona apunta que más que sanear el acto, lo que sucede es que transcurrido el plazo consolida los traspasos patrimoniales efectuados entre las partes, rescatando el planteamiento de Alfredo Barros Errázuriz.

Luego, el autor conecta la nulidad absoluta (ipso jure) con la eficacia de la nulidad relativa, que sí requiere de sentencia judicial, que tal como lo apunta, se desprende del mensaje del Código (\$36 mensaje). Explica que la nulidad en ciertos casos toma el nombre de relativa, ya que en sólo algunos pueden valerse de ella y en otros no, a diferencia de la absoluta, que en general cualquiera puede aprovecharse de ella siempre que tenga interés. Nos interesa destacar la conexión y coherencia que plantea Jorge Baraona entre este trabajo y otros que ha desarrollado, especialmente en el ámbito de la exigibilidad de las obligaciones. El cabal entendimiento de la figura de la nulidad relativa pasa por entender que la obligación que nace del contrato rescindible es inexigible al deudor beneficiado con la causal de nulidad relativa, a menos que ratifique el acto.

El planteamiento sobre la eficacia de la nulidad, judicial o de pleno derecho, es un tema que es necesario revisar, sobre todo teniendo a la vista la situación de los instrumentos de Derecho Contractual uniforme. Así, en los PECL la nulidad se produce por notificación extrajudicial (art. 4:112 de los PECL, y lo sigue el art. 3.15 de los PICC y el art. II.- 7:209 del DCFR. En todos estos instrumentos la nulidad tiene efectos restitutorios a pesar de su régimen extrajudicial (art. 4:115 de los PECL). Aunque somos conscientes, por lo menos en los PECL, que sus normas más bien están reducidas a los vicios de la voluntad como expresa el comentario oficial al art. 4:101 $\mathrm{PECL}^{3}$,

\footnotetext{
${ }^{3}$ Lando y Beale (2000) p. 227.
} 
y por expresa disposición excluyen la aplicación de las normas sobre ilegalidad, inmoralidad e incapacidad (igual que los PICC, art. 3.1. Sin embargo, el DCFR hace aplicable el estatuto de la nulidad a la infracción de normas de orden imperativas [mandatory rules], art. II.-7:101). Es decir, el régimen está estructurado para lo que nosotros entendemos como causales de nulidad relativa, aunque incorpora dentro de este régimen algunos casos de inexistencia o nulidad como el del error esencial, impediente u obstáculo. Empero, ésta parece ser la tendencia, por lo que cabe estudiar nuevamente el sistema nacional atendido las actuales exigencias del tráfico.

Hay un punto que nos hubiera 338 gustado ver tratado en la obra, que es el régimen general de la rescisión en el Código, más allá de la nulidad relativa. Aunque el mismo autor ya lo ha tratado en otra oportunidad, si bien a propósito de los vicios redhibitorios $^{4}$, hubiese complementado más aún su trabajo.

Hay otras cuestiones muy interesantes de destacar de la obra, como el problema de la conversión del acto nulo, la nulidad parcial y la nulidad de los actos administrativos. Sin embargo, sólo dedicaremos algunas palabras para comentar el problema de la indemnización de daños y la nulidad.

Como es sabido, el tema de la indemnización de daños con ocasión de la nulidad de un contrato se viene

${ }^{4}$ Véase Baraona González (2008) pp. 659-668.

estudiando a partir de la configuración de la culpa in contrahendo de Rudolph von Ihering. Sin embargo, en doctrina nacional son pocos los autores que se refieren al tema con alguna detención. El tema ofrece dificultades dogmáticas, no sólo por la compatibilidad de las acciones de nulidad e indemnizatoria sino porque pueden tener lugar, además, ciertas acciones restitutorias con ocasión de la nulidad del contrato, por lo que cabe diferenciarlas. Por otra parte, los intereses en juego también son diversos y complejos. Como apunta el autor, en algunas ocasiones hay ciertas personas que pueden verse arrastradas a la celebración del contrato, como en el caso del dolo, y que por la sola causa de las restituciones puede no quedar indemne. En otras situaciones una parte puede verse perjudicada ya no por la conducta de la otra parte, sino por las consecuencias que la nulidad apareja. Para estos efectos, Jorge Baraona se propone detectar varias hipótesis legales en las que se puede considerar bases suficientes para establecer un régimen general de daños con ocasión de la nulidad, sobre las que construye una responsabilidad de corte aquiliana, con base especial en las normas sobre vicios redhibitorios (que el autor considera de nulidad).

Esto nos obliga también a observar los instrumentos de Derecho Contractual uniforme en los que sí está tipificada la acción indemnizatoria en caso de nulidad con caracteres generales. Así, el art. 4:117 de los 
PECL (con similar redacción en los PICC, art. 3.18 y en el DCFR, art. II.7:213) permite la acción de perjuicios según el prisma del interés negativo, en contra del contratante que sabía o debía saber del error, dolo o amenaza o que tomó beneficio excesivo o posición injustamente ventajosa en el contrato. Las notas oficiales al artículo $^{5}$ nos informan que se trata de una materia ampliamente aceptada en el Derecho Comparado, lo que da origen a la redacción del precepto. Es probable que en la mayoría de los casos estemos frente a problemas de infracción deberes precontractuales de información como sucede con los vicios redhibitorios ${ }^{6}$. Más problemático parece ser la situación, como propone Jorge Baraona, de la parte que se ve perjudicada con la nulidad del contrato, independiente de la conducta anterior de las partes. Los casos más comunes es probable que incluyan la figura del dolo como factor de atribución; con todo, no cabe descartar la figura de la negligencia.

En suma, se trata de una obra muy interesante, aguda y original que da cuenta que los estudios sobre la nulidad no se agotan en las clásicas obras que tratan sobre el acto jurídico, como las de Luis Claro, los Arturo Alessandri, Víctor Vial o Ramón Domínguez, sino que es posible volver a estudiar y dogmati-

\footnotetext{
${ }^{5}$ Lando y Beale (2000) pp. 283-284.

${ }^{6}$ Véanse las ilustraciones en el comentario oficial a los PECL, op. cit., pp. 281-282.
}

zar el contenido de las instituciones clásicas del Derecho Civil. Incluso, la obra, además, presenta un gran aporte para otras áreas del Derecho, incluso, Público (sobre todo el capítulo noveno que trata sobre la nulidad civil y de Derecho Público). Con seguridad, las interpretaciones que propone el autor provocarán en el lector un cuestionamiento más profundo sobre los temas relativos al acto jurídico. Asimismo, el desarrollo dogmático contenido en la obra permite abocarse con nuevo espíritu crítico al estudio tanto de la normativa vigente como de los instrumentos de Derecho Contractual uniforme y de las futuras propuestas de reforma a los textos legales que con seguridad nacerán a partir de ellos. Por estas razones, sería muy deseable que esta obra llegue a comercializarse en Chile o publicarse en una editorial nacional, y así, sea posible tenerla a disposición en nuestro medio.

Juan Ignacio Contardo González

\section{Bibliografía CITADA}

Baraona González, Jorge (2008). "La acción redhibitoria como acción de nulidad", en Alejandro Guzmán BRITo (edit.) Estudios de Derecho Civil III. Santiago: Legal Publishing.

Lando, Ole \& Beale, Hugh (2000). Principles of European Contract Law. The Hague: Kluwe. 